Trojan Parlić, potpukovnik, dipl. inž.

Vladimir Bukarica, dipl. inž.

Tehnički remontni zavod,

Čačak

\section{POBOLJŠANJE MERENJA KARAKTERISTIKA RADIO-UREĐAJA AUTOMATIZACIJOM PUTEM PERSONALNOG RAČUNARA*}

UDC: $621.396 .6: 004.382 .7: 005.6$

Rezime:

U radu je prikazan sistem za merenje karakteristika radio-uređaja pomoću personalnog računara. Neophodni preduslovi za realizaciju ovakvog sistema su savremeni programabilni instrumenti sa standardizovanim interfejsima za povezivanje sa personalnim računarom, personalni računar i odgovarajući softver koji omogućava jednostavno upravljanje instrumentima, analizu, prezentaciju i arhiviranje rezultata. Takođe, prikazane su prednosti automatizovanog načina merenja u odnosu na tradicionalni, $i$ ispunjenje određenih zahteva iz standarda - sistemi menadžmenta kvalitetom JUS ISO 9001:2001.

Ključne reči: hardver, softver, virtuelni instrument.

\title{
IMPROVING MEASUREMENTS OF RADIO-DEVICE \\ CHARACTERISTICS BY INTRODUCING AUTOMATION AND PC
}

Summary:

A PC-based system for measuring radio-device characteristics is described in the study. Necessary prerequisites for the realization of such a system are state-of-the-art programmable instruments with standardized interfaces for PC connection, a PC and an adequate software enabling the control of instruments, analysis and data presentation and storage. The study also gives the advantages of automated measurement when compared to a traditional one as well as the fulfillment of certain requirements of standard JUS ISO 9001:2001 concerning quality management systems.

Key words: hardware, software, virtual instrument.

\section{Uvod}

Tehnički remontni zavod (TRZ) Čačak bavi se remontom sredstava naoružanja i vojne opreme KoV u Vojsci SCG. U okviru remonta sredstava veze i elektronike remont radio-uređaja (RU) zauzima veoma značajno mesto. Zbog velikog broja različitih radio-uređaja, provera karakteristika RU nakon remonta predstavlja složenu aktivnost koja uključuje složenu, raznovrsnu i skupu mernu opremu. U TRZ Čačak remont RU je identifiko-

Rad je saopšten na Nacionalnoj konvenciji o kvalitetu 2004. održanoj od 20. do 24. juna u Beogradu. van kao proces u smislu standarda JUS ISO 9001:2001 (Standard). Proces remonta RU ima više faza: prijem (u skladište) u TRZ, dopremanje u remontni pogon, defektacija, rasklapanje (na sklopove i podsklopove), opravka, podešavanje, završno merenje karakteristika (i predaja kontroli kvaliteta), predaja u skladište i otprema (predaja korisniku). Jedna od najznačajnijih faza svakako je merenje karakteristika radi provere kvaliteta remonta uređaja. Postoji potreba da se ova faza automatizuje radi podizanja na viši nivo i sprečavanja pojavljivanja neusaglašenosti u ovoj fazi. 


\section{Tradicionalni način merenja}

Najčešće veličine koje se mere nakon remonta RU su: tačnost frekvencije (na kanalu, frekvenciji), potrošnja energije (u prijemu, predaji), osetljivost uređaja, merenje devijacije noseće frekvencije radio-predajnika, merenje VF izlazne snage, merenje NF snage, merenje odnosa signal/šum i spektar izlaznog signala.

Postoji nekoliko vrlo važnih radnji pre svakog merenja. Neke od najosnovnijih radnji moguće je svrstati u sledeće grupe:

- izbor merne metode;

- pravilna upotreba merne metode $\mathrm{i}$ mernih instrumenata;

- zapisivanje podataka (zapisnik o merenju);

- prikazivanje rezultata merenja (izveštaj o merenju).

Navedene radnje definisane su u tehničkoremontnoj dokumentaciji (TRD) za svaki RU. TRD definiše mernu instrumentaciju koju najčešće čine: signal-generator, digitalni multimetar (univerzalni instrument), digitalni frekvencmetar (brojač frekvencije), katodni osciloskop, analizator spektra, merač VF snage, merač NF snage, merač modulacije, generator proizvoljnih talasnih oblika (ton generator), izvor stabilisanog napona i drugi. Radi merenja pojedinih karakteristika (veličina) koriste se različite kombinacije ovih uređaja u različitim režimima rada, različito međusobno povezani i različito povezani na RU.

Celokupni proces merenja je manuelni, sa operatorom odgovornim za sve radnje u procesu merenja: kalibracija, povezivanje, podešavanje režima rada, izbor opreme, očitavanje i zapisivanje rezultata i izrada izveštaja o merenju (kontrolno-mernog lista).
Ovakav način merenja je nepraktičan i spor, zahteva mnogo instrumenata na radnom mestu, povećava mogućnost oštećenja instrumenata i RU zbog pogrešnog povezivanja ili neodgovarajućeg režima rada, pogrešnog očitavanja ili pogrešnog zapisivanja rezultata merenja. Mogućnost nastanka greške je sve veća što je veći broj instrumenata koji učestvuju u merenju, odnosno veći broj veličina koje se mere.

U TRZ Čačak izvršeno je praćenje i analiza procesa merenja karakteristika radio-uređaja u pogledu mogućnosti pojave grešaka pri merenju. Proučavanje mernih grešaka je početni korak u pronalaženju načina da se one što je moguće više smanje.

Pojam merna greška upotrebljava se u svim granama nauke. Svaka se od tih grana služi različitim mernim postupcima i pri tome koristi mnogobrojne merne uređaje. Jasno je, stoga, da se može napraviti prilično veliki spisak uzroka koji dovode do mernih grešaka. Međutim, bez obzira na sve to, merne greške je moguće svrstati u tri grupe [1]: grube, sistematske i slučajne greške.

U tabeli su prikazane osnovne merne greške i opisani neki uzroci grešaka iz kojih se mogu sagledati načini na koje se one mogu smanjiti ili eliminisati.

Iz tabele je uočljivo da je potrebno na nov način upravljati resursima (ljudskim i infrastrukturnim) radi ispunjavanja zahteva Standarda (tačka 6.2 i 6.3). Svakako najbolji način za to je proces merenja automatizovati i ulogu operatera zameniti računarom, a umesto klasičnih instrumenata koristiti tehnološki naprednije programabilne instrumente. 


\begin{tabular}{|c|c|c|c|}
\hline \multicolumn{4}{|c|}{ Merne greške } \\
\hline \multirow[b]{2}{*}{ Grube greške } & \multicolumn{2}{|c|}{ Sistematske greške } & \multirow[b]{2}{*}{ Slučajne greške } \\
\hline & Greške metode i opreme & $\begin{array}{l}\text { Greške usled subjektivnih } \\
\text { faktora i uticaja sredine }\end{array}$ & \\
\hline $\begin{array}{l}\text { Uzroci: } \\
\text { - nepažnja ispitivača } \\
\text { - neobučenost ispitivača } \\
\text { - neadekvatan izbor opreme } \\
\text { - netačno zapisivanje i } \\
\text { računanje }\end{array}$ & $\begin{array}{l}\text { Uzroci: } \\
\text { - pogrešan merni postupak } \\
\text { - neispravna ili neverifiko- } \\
\text { vana oprema }\end{array}$ & $\begin{array}{l}\text { Uzroci: } \\
\text { - fizički i psihički nedostaci } \\
\text { ispitivača } \\
\text { - promene parametara sre- } \\
\text { dine }\end{array}$ & $\begin{array}{l}\text { Uzroci: } \\
\text { - nepoznati faktori koji } \\
\text { dovode do malih varija- } \\
\text { cija prilikom merenja }\end{array}$ \\
\hline
\end{tabular}

\section{Arhitektura savremenog mernog sistema}

Savremeni merni sistem podrazumeva povezivanje radio-uređaja, mernih instrumenata i personalnog računara kao i realizaciju svih potrebnih veza.

Blok-dijagram instrumentacionog (mernog) sistema prikazan je na slici 1.

Uređaj za testiranje je proizvod ili komponenta koja se testira (u ovom slučaju RU).

Interfejs resursa sistema je mesto $u$ mernom sistemu gde su svi signali od instrumenata raspoloživi. To je obično grupa konektora sa kablovima koji se vraćaju nazad do instrumenata u sistemu. Ovi konektori signala su svi u jednom centralnom mestu da bi omogućili lak pri-

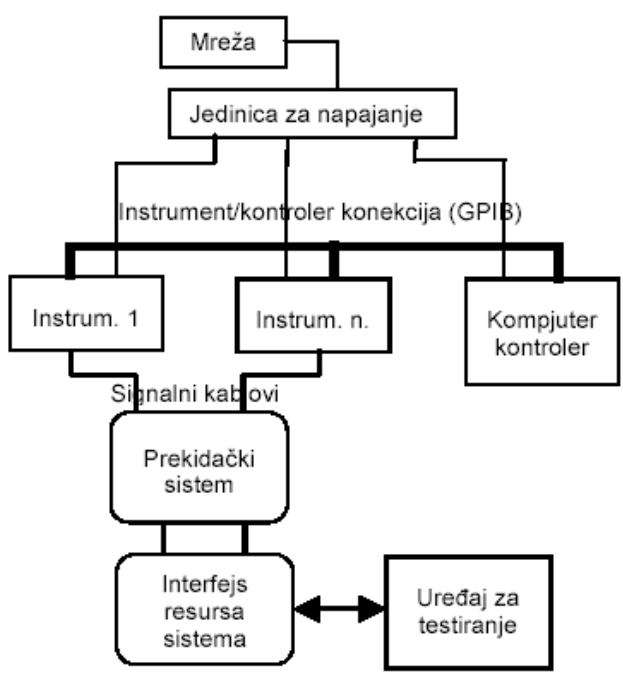

Sl. 1 - Blok-dijagram hardvera sistema stup uređaju za testiranje. Zbog jednostavnosti povezivanja uređaja ovaj resurs sistema nije iskorišćen.

Prekidački sistem je neophodan $u$ instrumentacionom sistemu radi usmeravanja (route) instrumenata na uređaj za testiranje. Prekidački elementi zastupljeni su zbog potrebe ostvarivanja svih veza između instrumenata i instrumenata i radio-uređaja. Signalni kablovi koriste se za povezivanje instrumenta sa uređajem za testiranje.

Instrumenti $1 \ldots \mathrm{n}$ su uređaji koji se koriste za tekuća merenja. Postoje tri glavna tipa instrumenata: merni, instrumenti za pobuđivanje (stimulaciju) i prekidački (za usmeravanje mernih i pobudnih signala na uređaj za testiranje). U ovom slučaju instrument sa prekidačkom jedinicom ujedno je i prekidački sistinstrument/kontroler, a konekcija je deo sistema koji povezuje računar sa instrumentima. Preko konekcije upravlja se instrumentima i povratno dobijaju merni podaci. Postoji mnogo tipova instrument/kontroler sistema za povezivanje, od kojih su najpoznatiji: IEEE 488 bus, PC bus, VXI bus, PXI bus, USB, LAN connections i Ethernet. Kompjuter kontroler je kompjuter koji upravlja instrumentima (u ovom slučaju personalni računar). Jedinica za napajanje snabdeva naizmeničnim naponom instrumente $\mathrm{i}$ kontroler. 
Korisnik danas nije limitiran tipom instrumenata kojim upravlja, ukoliko izabere upravljačku tehnologiju standardizovanu u industriji. Mogu se koristiti instrumenti različitih kategorija kao: serial, GPIB, VXI, PXI, computer - based instruments, Ethernet, SCSI, CAMAC i parallel port devices (imena kategorija se odnose na komunikacioni interfejs). GPIB komunikacija je najstarija i danas je podržana od svih najznačajnijih svetskih proizvođača mernih instrumenata.

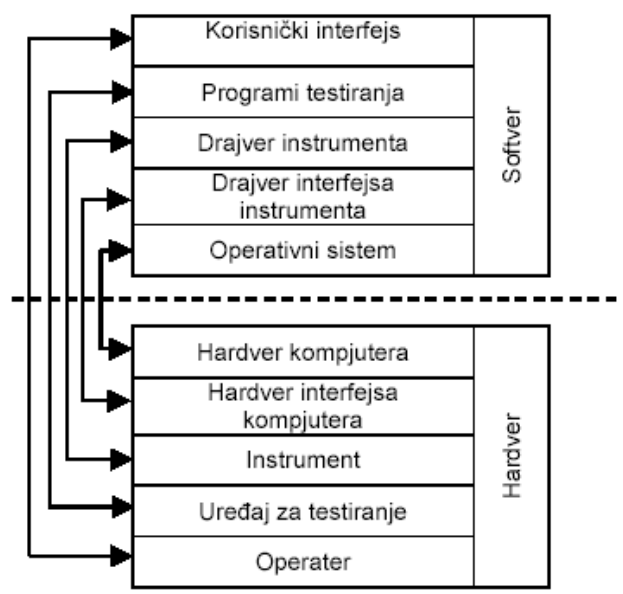

Sl. 2 - Blok-dijagram veze softvera i hardvera

ANSI/IEEE Standard 488.1-1987, takođe poznat kao General Purpose Interface Bus (GPIB), opisuje standardni interfejs za komunikaciju između instrumenata i kontrolera različitih isporučilaca. Sadrži informacije o električnim, mehaničkim i funkcionalnim specifikacijama. GPIB je digitalni, 8-bitni paralelni komunikacioni interfejs sa brzinom protoka podataka od $1 \mathrm{Mbyte} / \mathrm{s}$ i više, koji koristi trožični prenos (handshake). Magistrala podržava jedan System Controller, obično kompjuter, i najviše 14 instrumenata. ANSI/IEEE Standard 488.2-1992 proširuje IEEE 488.1 tako što definiše komunikacioni protokol magistrale, opšti set kodova i formata podataka i generički set opštih komandi za uređaje.

Svi GPIB uređaji i interfejsi moraju imati jedinstvenu GPIB adresu između 0 i 30. Adresa 0 dodeljuje se GPIB interfejsu. Instrumenti na GPIB magistrali mogu koristiti adrese $1-30$. GPIB uređaji mogu biti predajnici, prijemnici i kontroleri. Predajnici šalju poruke podataka, a prijemnici primaju poruke podataka. Kontroler, obično kompjuter, upravlja protokom informacija na magistrali. On definiše komunikacione linkove i šalje GPIB komande uređajima. Najbolji način da se razume arhitektura softvera $i$ veza sa hardverom je grupisanje softvera sa hardverom koji kontroliše (slika 2). Svaka hardverska komponenta na slici 1 upravljana je odgovarajućim softverskim nivoom. Na slici 2 ta veza je prikazana strelicama sa leve strane blokova. Tako, na primer, drajver instrumenta upravlja instrumentom.

Savremeni mikroprocesorski instrumenti sadrže „kompjuterski interfejs“ koji omogućuje komunikacioni kanal između ugrađenog mikroprocesora i eksternog kompjutera. Softverski interfejs prema instrumentu je u velikoj meri nezavisan od hardverske konekcije zahvaljujući sledećim standardima: IEEE 488.2 i SCPI (Standard Commands For Programmable Instruments) i VISA (Virtuel Instrument Software Architecture). IEEE 488.2 opisuje sintaksu koju su instrumenti prihvatili. SCPI opisuje aktuelno značenje komandi formiranih koristeći IEEE 488.2 sintaksu. SCPI je u osnovi rečnik svih komandi i upita (queries) ko- 
je instrument treba da prepozna. Ključni deo SCPI je standardni model instrumenta koji omogućava konzistentni pogled instrumenta sa softverske tačke gledišta. Model instrumenta prikazan je na slici 2. SCPI komande za upravljanje instrumentom zasnovane su na onome što blok $u$ modelu izvršava za datu funkciju. Instrumentacioni model na slici 2 je najopštiji, i opisuje merne instrumente (gornji red) i instrumente za pobudu (donji red). Od tipa instrumenta zavisi koje će blokove instrumentacionog modela sadržati određeni instrument i bliže se daje uputstvima proizvođača.

VISA je VXIplug\&play I/O softverski jezik koji predstavlja osnovu za softversku standardizaciju VXIplug\&play udruženja za sisteme. VISA sama po sebi ne omogućava programiranje instrumenata, već predstavlja API (Application Programming Interface) visokog nivoa koji poziva drajvere na niskom nivou. VISA može upravljati VXI, GPIB, serial ili computer - based instrumentima i pozivati odgovarajući drajver u zavisnosti od tipa instrumenta koji se koristi. VISA je biblioteka funkcija koju korisnik koristi za komumnikaciju sa VXI, GPIB, serial ili computer - based instrumentima.

Na slici 4 prikazana je struktura implementacije aplikacije. Programski jezici (paketi) mogu se podeliti u četri grupe:

- klasični programski jezici: FORTRAN, C, Basic i dr.,

- objektno-orijentisani programski jezici: $\mathrm{C}++$, Visual Basic,

- test/instrument-based jezici: ATLAS, Rocky Mountain Basic i dr.,

- programski paketi sa grafičkim programiranjem: VEE Pro, LabVIEW i dr.

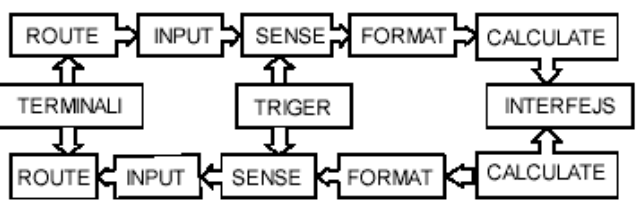

Sl. 3 -SCPI model instrumenta

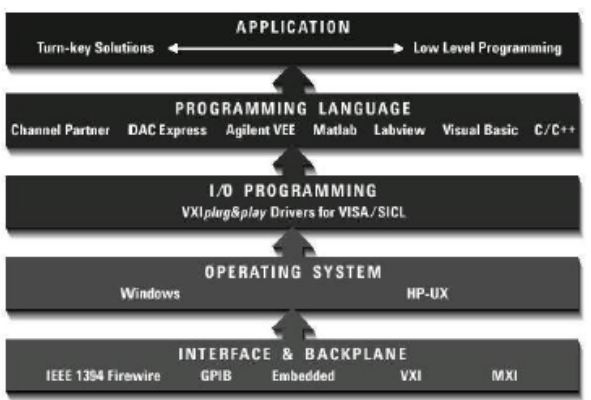

Sl. 4 -Implementacija aplikacije

Poslednja grupa olakšala je upravljanje instrumentima uvođenjem novih standarda za drajvere instrumenata (objedinjuju drajver instrumenta i drajver interfejsa instrumenta). Aplikacije u ovim okruženjima nazivaju se virtuelni instrumenti.

\section{Virtuelni instrument $u$ automatizaciji merenja}

Pod virtuelnim instrumentom (VI) podrazumeva se kombinacija hardverskih i softverskih elemenata sa personalnim računarom kojima se ostvaruje funkcija klasičnog instrumenta. Virtuelni instrument je organizovan hijerarhijski i modularno. Hijerarhijskom i modularnom organizacijom obezbeđen je koncept modularnog programiranja. Komunikacija sa programabilnim instrumentima ostvaruje se preko instrumentacionih drajvera. Instrumentacioni drajver predstavlja skup virtuelnih instrumenata preko kojih se komunicira sa instrumentom korišćenjem standardnih VISA (Virtual Instrument Software Architecture) I/O funkcija. Po- 
zvani drajver automatski šalje komande $u$ vidu nizova karaktera koji odgovaraju određenom instrumentu.

$\mathrm{Na}$ slici 5 prikazana je osnovna struktura drajvera instrumenta za programski paket LabVIEW. Osnovne elemente drajvera predstavljaju prednja ploča (Soft Front Panel) (slika 7) i blok-dija-

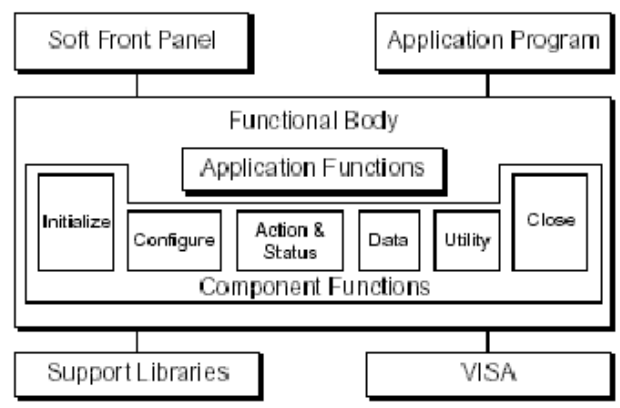

Sl. 5 - Opšti model drajvera instrumenta tor panes) i može ih pozivati aplikacija višeg hijerarhijskog nivoa radi izvršavanja određenih zadataka.

Komponente drajvera nižeg hijerarhijskog nivoa kao što su inicijalizacioni VI (Initialize VI), konfiguracioni VI (Configuration VI), akcioni (Action VI) i statusni VI (Status VI), VI podataka (Data VI), uslužni VI (Utility VI) i VI za završavanje komunikacije (Close VI) međusobno se spajaju u jedan VI višeg hijerarhijskog nivoa i izvršavaju navedenim redosledom.

Na slici 7 prikazan je primer prednje ploče osciloskopa HP54645D koncipiranog kao virtuelni instrument. Može se uočiti da na prednjoj ploči virtuelnog instrumenta nisu predstavljene sve komande i funkcije pravog osciloskopa, već sa-

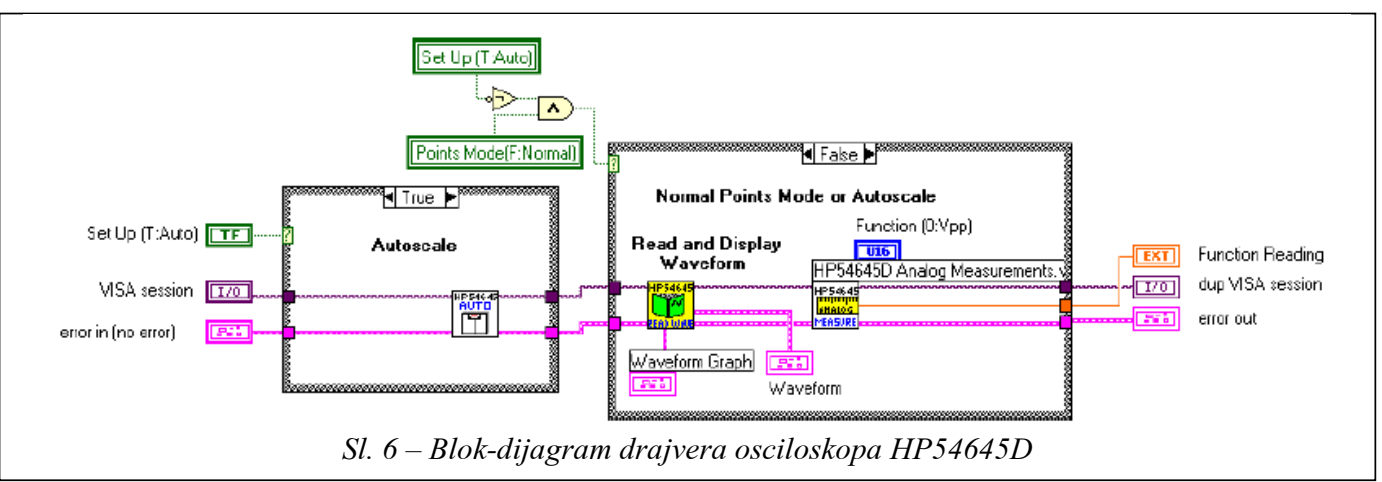

gram (Functional Body), kao izvršni program drajvera. Aplikacioni VI predstavljaju najviši nivo u hijerarhiji drajvera instrumenta. Oni su sačinjeni u G-blok dijagram-kodu, odnosno koristeći grafičko programiranje, mogu izvršavati konfigurisanje instrumenta ili merenje pozivanjem odgovarajućih VI komponenti nižeg hijerarhijskog nivoa. Aplikacioni VI predstavljeni su pomoću ikone sa odgovarajućim priključnim poljima (connec-

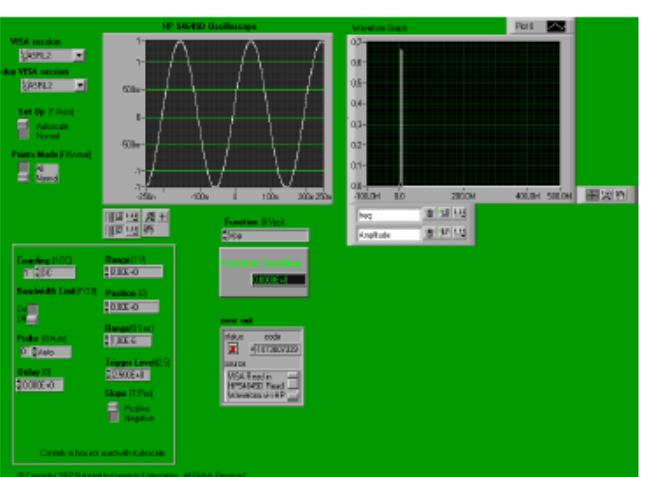

Sl. 7 - Prednja ploča virtuelnog instrumenta 
mo one koje su od interesa za konkretnu aplikaciju. Takođe, moguće je izvršiti modifikaciju prednje ploče dodavanjem još jednog ili više ekrana na kojima se mogu posmatrati različite transformacije ulaznog signala.

Pomoću prikazanog softvera, korišćenjem virtuelnih instrumenata, odnosno drajvera za klasične instrumente, osnovnih elemenata i struktura programskog paketa LabVIEW može se napraviti aplikacija koja u potpunosti automatizuje proces merenja. Potpuno su jednoznačno određeni tip instrumenata, zadate veličine, merna područja $i$ podešenost instrumenata. Izrada izveštaja vrši se automatski. Na taj način eliminiše se mogućnost nastanka grešaka navedenih u tabeli.

\section{Sistem za merenje}

Na osnovu poznavanja veličina koje se zadaju i mere, kao i karakteristika mernih instrumenata i softvera, definisan je merni sistem koji se može koristiti za automatizaciju merenja na RU:

- generator signala HP 8648A, 100 $\mathrm{kHz}-1000 \mathrm{MHz}$,

- osciloskop, digitalni, memorijski, HP54645D, $100 \mathrm{MHz}$ (2 analogna i 16 digitalnih kanala),

- agilent 34970A Data Acquisition/Switch Unit,

- agilent E3645A Power Suply (ili izvor stabilisanog napona IN 35/10 TRAVNIK),

- agilent E4403B analizator spektra, $9 \mathrm{kHz}-3 \mathrm{GHz}$,

- personalni računar sa Windows 98 OS, C programski jezik, LabVIEW programski paket, CEC 488 GPIB interfejs.
Svi instrumenti imaju GPIB interfejs i podržavaju softverske standarde za upravljanje instrumentima IEEE 488.21997, SCPI Version 1992.0 i VISA.

\section{Izlazne datoteke i zapisi}

Aplikacije formiraju izlazne datoteke sa odbircima izmerenih veličina koje se mogu „uvoziti“ u programe za dalju obradu i prezentaciju, kao npr. Word ili Excel. Zapisi mogu biti i u vidu slike koja predstavlja izgled ekrana klasičnog instrumenta u jpg, bmp ili nekom sličnom formatu.

Na slici 8 prikazan je izgled ekrana analizatora spektra dobijen pomoću softvera Intui Link, što se može koristiti za izradu kvalitetnijih zapisa. Osim slike, softver omogućava i prenos podataka o snimljenom signalu (ukupno 401 odbirak) sa instrumenta na računar radi formiranja baze podataka. Na slici 9 prikazan je dijagram spektra signala dobijen od podataka smeštenih u Excel tabelu. Pored podataka o izmerenoj veličini u tabelu se smeštaju podaci o podešenosti instrumenta, modelu instrumenta kojim je izvršeno merenje i nje-

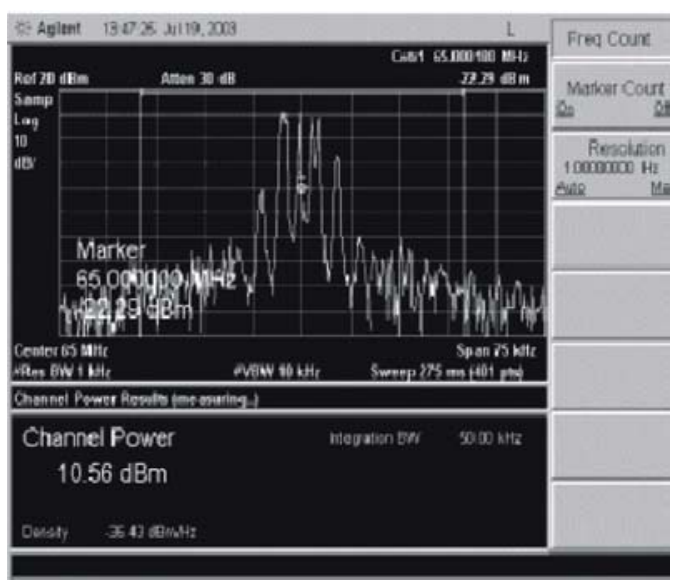

Sl. 8 - Ekran analizatora spektra 
govom serijskom broju. Tabelarni i grafički način prikazivanja stvaraju osnovu za formiranje izveštaja (protokola) o ispitivanju radio uređaja.

\section{PSAJESA Spectrum Analyzer} (E4403B)

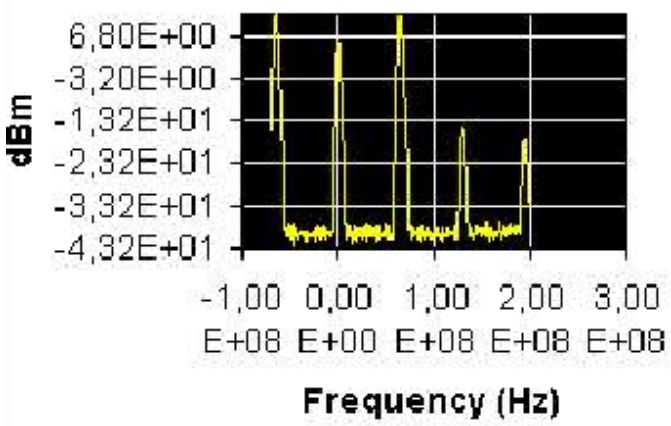

Sl. 9 - Dijagram spektra signala dobijen iz Excel tabele

\section{Zaključak}

Standard JUS ISO 9001:2001 podstiče usvajanje procesnog pristupa radi ispunjenja zahteva korisnika. Model sistema menadžmenta kvalitetom ukazuje na veze procesa neophodnih za taj sistem, a koje se odnose na aktivnosti menadžmenta, obezbeđenje resursa, realizaciju i merenje karakteristika proizvoda i procesa.

Automatizacija merenja, prikazana u radu, prožima više procesa iz Standarda i obezbeđuje zadovoljenje zahteva iz tačke 6.2. (ljudski resursi), tačke 6.3. (infrastruktura), tačke 7.6. (upravljanje uređajima za praćenje) i 8.2.4. (praćenje i merenje karakteristika proizvoda).

Iskustva iz automatizacije opisana $\mathrm{u}$ radu mogu se koristiti i za druge procese $\mathrm{u}$ okviru remonta sredstava veze i elektronike, kao i na druge faze u okviru procesa vezanih za remont sredstava veze $\mathrm{i}$ elektronike.

Literatura:

[1] Grupa autora, 2003, IIS - SISTEM KVALITETA ISO 9001:2000, Istraživački tehnološki centar, Novi Sad.

[2] Drndarević, V., 2000, Akvizicija mernih podataka pomoću personalnog računara, Institut za nuklearne nauke Vinča, Beograd.

[3] Agilent Technologies 1999, Esa Spectrum Analyzers Measurement Guide.

[4] NI-VISA User Manual, 1998, Part Number 321074D-01.

[5] Mamula, V.: 1985, Merenja u elektronici, Mornaričkotehnička uprava, Beograd. 
